\title{
Productivity and Economic Growth in East Asia: Innovation, Efficiency and Accumulation*
}

\author{
Gaofeng Han \\ Department of Economics \\ University of California, Santa Cruz \\ Kaliappa Kalirajan \\ GRIPS/FASID Joint Graduate Program \\ Tokyo \\ Nirvikar Singh \\ Department of Economics \\ University of California, Santa Cruz
}

\footnotetext{
${ }^{*}$ This research was generously supported by the Pacific Rim Research Program of the University of California. We are grateful to seminar audiences at GRIPS/FASID in Tokyo and ICRIER in New Delhi for helpful comments and discussions. In particular, we wish to thank Yujiro Hayami, Keijiro Otsuka, K.L. Krishna, Bishwanath Goldar and Vivek Srivastava for important comments and suggestions. However, we alone are responsible for remaining shortcomings.
} 


\title{
Productivity and Economic growth in East Asia: Innovation, Efficiency and Accumulation
}

\begin{abstract}
Sources of growth in East Asia have been a controversial subject in the literature. This necessitates more empirical studies to see whether there is more convergence to a particular view of the sources of growth. This study provides a comprehensive examination of sources of growth that allows one to decompose total factor productivity growth, separating out technical efficiency changes from technological progress. This paper applies a varying coefficients frontier production function model to data from 20 manufacturing sectors at the 3-digit SIC level to examine the sources of growth in four East Asian economies. The economies are Hong Kong, Singapore, Japan and South Korea, and the period covered is 1987-93. We find that while there is ample evidence of the importance of increasing inputs in growth, and there is some support for technical efficiency change, or catching up to the frontier over this period, there is weak or even negative evidence for the role of technological progress, measured as a shift in the estimated production frontier.
\end{abstract}




\section{Introduction}

In the 1980s and early 1990s, several East Asian countries achieved seemingly miraculous growth, dramatically changing the standard of living of people in these countries. As a result, debates on the sources of high and sustained economic growth in economies such as Hong Kong, Singapore, South Korea and Japan have increasingly attracted the attention of economists around the world. While the recent financial crisis in East Asia has shifted attention to short run problems, understanding the sources of East Asia's growth remains critical for the long run welfare in the Pacific Rim.

Many studies of East Asian economies have been conducted recently. To mention a few, the World Bank (1993) and Hughes (1995) investigated the role of public policy in economic development, particularly of East Asia; Kim and Lau (1994), Young (1992, 1995) and Krugman (1994) emphasized the crucial role played by capital accumulation in the high performing East Asian economies; Singh and Trieu (1997, 1999) focused more on the contribution of technological change to East Asian growth. However, in the above studies, there is an implicit assumption that the economies are producing on their frontiers with full technical efficiency and there are no gaps between actual and potential outputs. This further implies that the economies have been applying the best practice techniques of their relevant chosen technologies.

If the production process were simply the engineering relationship between a set of inputs $x_{i t}$ and observed output $y_{i t}$, then a well-defined production function would describe the process accurately and any variation in inputs would result in a corresponding change in output. However, in reality, observed output is often the result of a series of economic decisions, which influence the method of application of inputs, and so the variables associated with the relevant economic institution will also play an important part in an economy's output. For this reason alone, some economies may be producing not on but inside the frontiers with an actual gap between 'best practice' techniques and realized methods of production owing to the negative effects of non-price or organizational factors. The objective of this paper is to examine, compare and identify the sources of productivity performance and economic growth in East Asia, incorporating the reality of the existence of the above discussed 'output gap' and to draw possible policy implications for reforming economies and other countries in the Pacific Rim and 
elsewhere. In this paper, we focus on four economies: Hong Kong, Japan, Singapore and South Korea. We use data for the period 1987-93. In work in progress, we are extending the results of this paper to include Taiwan, and to significantly longer time periods.

The structure of the paper is as follows. Section 2 briefly discusses the conclusions of some of the important studies on the East Asian growth. The methodology followed in this paper is explained in Section 3. Section 4 gives a description of the data used, and an overview of the performance of the economies studied, during the period that we analyze. In Section 5, we present the empirical results for the case where we analyze each economy individually. Section 6 provides an alternative analysis, where we organize the data by sectors, pooling observations across economies. The final section summarizes out the overall conclusions of this study.

\section{TFP Growth in East Asia}

There are many studies on TFP growth in East Asia, and we discuss just a small sample here. Felipe (1999) provides a critical survey of some of the literature. We discuss the following studies: Young (1992, 1994 and 1995), Kim and Lau (1994), Fischer (1993), Marti (1996), Collins and Bosworth (1997), Singh and Trieu (1999), Hayami and Ogasawara (1999) and Sonobe and Otsuka (2001). The methodology that has been followed by most studies is the growth accounting method (a translog production function under the assumption of constant returns to scale and perfect competition). All these studies mentioned with the exception of Sonobe and Otsuka measure TFP growth as a whole, and are unable to decompose it into efficiency change and technological progress. Most of these studies show that output growth in East Asia since the 1960s can be accounted for chiefly by input growth in physical or human capital and labor, with little left over to be attributed to technological change. Such results would therefore imply that the TFP growth performance in this region does not seem to be outstanding compared to the rest of the world. We next discuss some of the studies in more detail.

Young (1992) used the growth accounting approach to estimate TFP growth for Singapore and Hong Kong. He concluded that the average value of the Solow residual for Singapore was zero, if not negative, for the previous thirty years. The TFP contribution to output between 1974 and 1989 was about $-0.004 \%$ to $-6 \%$ without allowing for heterogeneity in inputs, 
or $-8 \%$ from 1970 to 1990 with differentiated inputs. Capital accumulation explained essentially all of the increase in output per worker during this period. Negative TFP contribution was also found in the manufacturing sector (Young, 1995). For Hong Kong, on the other hand, TFP contributed about $30 \%$ to $50 \%$ of output growth. Young (1995) extended his earlier work to include the economies of South Korea and Taiwan as well. He found positive rates of productivity growth for 1960-1990. For Korea, the annual contribution of TFP for the overall economy for the period 1966-1990 was $16.5 \%$ of overall growth. For the manufacturing sector, it accounted for $20 \%$ of overall growth of the sector.

Young (1994) used an alternative estimation method to calculate TFP growth for Hong Kong and Singapore. He regressed the output growth rate per worker on a constant and the growth of capital per worker for the period 1970-1985 using cross-country data constructed from the Penn World Tables. The capital stock was constructed by the perpetual inventory method with the accumulating investment flows for 1960-1969 as benchmark, and 6\% depreciation rate. These results were consistent with his others, in that TFP growth in Hong Kong was high and nonexistent in Singapore. Fischer (1993) used the growth accounting method to estimate three sets of TFP growth rates, each with a different weight for labor and capital, on data from the Penn World Tables. Again he obtained a negative TFP growth rate for Singapore. Marti (1996) examined Young's (1994) results with slightly fewer countries but more periods than Young's data set, again using the Penn World Tables. She obtained a positive TFP contribution to the growth rate for Singapore.

Kim and Lau (1994) used a fixed effect model combined with a meta-production function approach, which was first discussed by Hayami and Ruttan (1985), for pooled data across countries for Japan, Hong Kong, South Korea, Singapore, Taiwan and some other countries. They found that for data from the mid-1960s to early 1990s the null hypothesis that the TFP growth rate for Hong Kong, Singapore, Korea and Taiwan was zero could not be rejected.

Singh and Trieu (1999) analyzed data for Japan, South Korea and Taiwan by the growth accounting approach and found a positive and significant role of technological change in these economies' growth. They found that Japan had the highest TFP contribution to output growth 
over the period $1965-1990,44 \%$ of the output growth. Korea had $42 \%$ TFP contribution to output growth. Collins and Bosworth (1997) also obtained positive results of TFP growth for Eastern Asian economies using growth accounting for a large set of countries. They concluded that TFP growth rate was positive in East Asia, but not extraordinary high compared to that of other regions. Further, factor accumulation was more important to the output growth over period 1965-1990.

Using historical data from the United States and Japan combined with the growth accounting method, Hayami and Ogasawara (1999) showed that the contribution of TFP growth was small in the early stages of economic development before the improvement of human capital in later periods. The study by Sonobe and Otsuka (2001) is different from the above studies in the sense that they decompose the overall labour productivity growth into the effect of overall capital accumulation and the effect of overall TFP growth. Nevertheless, they used the growth accounting approach.

\section{Empirical Methodology}

A variety of techniques have so far been developed to measure total factor productivity growth under different assumptions (Fried, Lovell and Schmidt, 1993). With the realistic assumption that there is significant output gap in the East Asian economies, the objective here is to decompose output growth into growth due to input growth, due to changes in the output gap, and due to technological progress. Nishimizu and Page (1982) attempted such a decomposition to examine total factor productivity growth in Yugoslavia for the period 1965-1978. They used a deterministic frontier production function approach, which does not allow various statistical testing of hypotheses concerning productivity. A recently developed technique, the varying coefficient production frontier approach, facilitates statistical testing of hypotheses along with analysis of total factor productivity growth by isolating the catching up to the production frontier (reductions in the output gap) from shifts in the production frontier (technological progress) (Kalirajan and Obwona, 1994). Applying this method to the industry level means that, an industry obtains its full technical efficiency without any output gap by following the best practice techniques given the technology. In other words, technical efficiency is determined by the method of application of inputs in industries, regardless of the levels of inputs (that is, scale of operation). This implies that different methods of applying the same inputs will influence the 
output differently, and the slope coefficients will vary from sector to sector. This varying coefficient production frontier approach is an improvement over the conventional constant-slope production frontier approach to measuring technical efficiency (Aigner et al, 1977; Meeusen et al, 1977).

The distinction between technical efficiency change that arises due to variations in the method of application of inputs and technological progress in the varying coefficient approach offers an additional important dimension to the policy relevance of total factor productivity studies. Technical efficiency change measures whether the output gap between "best practice" techniques and realized production methods is diminishing or widening over time: this effect can be substantial, and may outweigh gains from technical progress itself. It is, therefore, important to know how far one is off the production (technology) frontier at any point in time, and how quickly one can reach the frontier. For instance, in the case of developing economies that borrow technology extensively from abroad, failure to acquire and adapt new technology will be reflected in the lack of shifts in the frontier over time. Technological progress, on the other hand, measures the movement of the production or technology frontier over time. It reflects the success of explicit policies to facilitate the acquisition of foreign technology, and can be interpreted as providing a measure of innovation.

The decomposition of total factor productivity growth into technical efficiency change (output gap changes or catching-up) and technological improvement is, therefore, useful in distinguishing innovation or adoption of new technology by "best practice" industries from the diffusion of technology. Co-existence of a high rate of technological progress and a low rate of change in technical efficiency may reflect failures in achieving technological mastery or diffusion.

A brief explanation of the varying coefficient frontier approach is given below. Using the varying coefficient model, the frontier coefficients are obtained and the time- and countryspecific potential outputs are calculated. Then, the extent of the output gap is determined. Finally, output growth is decomposed into growth rates due to technical efficiency change, 
technological improvement and input contribution. It should be noted here that both technical efficiency change and technological improvement are examined for a given level of inputs.

\subsection{The Varying Coefficients Stochastic Frontier model}

Assuming a Cobb Douglas production technology, the varying coefficients stochastic production frontier can be written as follows:

$$
\begin{aligned}
& \ln Y_{i t}=\alpha_{1 i}+\sum_{j=2}^{T} \gamma_{j t} D_{j i t}+\sum_{k=2}^{K} \alpha_{k i} \ln X_{k i t} \\
& i=1, \ldots, N . \quad t=1, \ldots, T
\end{aligned}
$$

where $\alpha_{1 i}=\bar{\alpha}_{1}+u_{1 i} ; D_{j i t}=1$ if $\mathrm{j}=t$ and zero otherwise; and $\mathrm{Y}_{\mathrm{it}}$ is the output level of the $\mathrm{i}^{\text {th }}$ firm in period $\mathrm{t} ; \mathrm{X}_{\mathrm{kit}}$ is the level of the $\mathrm{k}^{\text {th }}$ input used by the $\mathrm{i}^{\text {th }}$ firm in period $t ; \alpha_{1 i}$ is the intercept term for the $\mathrm{i}^{\text {th }}$ firm; $\alpha_{k i}$ is the actual response of the output to the method of application of the $\mathrm{k}^{\text {th }}$ input by the $\mathrm{i}^{\text {th }}$ firm; and $u_{k i}$ refers to the random variable term which has mean zero and variance $\sigma_{u k k}$. Let

$$
\alpha_{k i}=\bar{\alpha}_{k}+u_{k i} ; \quad \mathrm{k}=1,2, \ldots \mathrm{K} \text { and } \mathrm{i}=1,2, \ldots \mathrm{N}
$$

where,

$$
\begin{aligned}
& E\left(\alpha_{k i}\right)=\bar{\alpha}_{k}, \\
& E\left(u_{k i}\right)=0 \text { and } \\
& \operatorname{Var}\left(u_{k i}\right)=\sigma_{u j k} \text { for } \mathrm{j}=\mathrm{k} \text { and } 0 \text { otherwise. }
\end{aligned}
$$

With these assumptions, model (1) can be written as

$$
\ln \mathrm{Y}_{\mathrm{it}}=\bar{\alpha}_{1}+\sum_{\mathrm{j}=2}^{\mathrm{T}} \bar{\gamma}_{\mathrm{j}} \mathrm{D}_{\mathrm{jit}}+\sum_{\mathrm{k}=2}^{\mathrm{K}} \bar{\alpha}_{\mathrm{k}} \ln \mathrm{X}_{\mathrm{kit}}+\mathrm{w}_{\mathrm{ki}}
$$

where

$$
\begin{aligned}
& w_{k i}=\sum_{k=2}^{K} u_{k i} \ln X_{k i t}+u_{1 i} \\
& E\left(w_{k i}\right)=0 \text { for all } \mathrm{i} \text { and } k
\end{aligned}
$$




$$
\begin{aligned}
& \operatorname{Var}\left(w_{k i}\right)=\sigma_{u 11}+\sum_{k=2}^{K} \sigma_{u k k} \ln ^{2} X_{k i t} \\
& \operatorname{COV}\left(w_{k i}, w_{j i}\right)=0 \text { for } k \neq j .
\end{aligned}
$$

Following the estimation procedures suggested by Hildreth and Houck (1968), the mean response coefficients $\left(\bar{\alpha}\right.$ 's) and the variances $\left(\sigma_{u k k}\right)$ can be estimated and the individual response coefficients ( $\alpha_{k i}$ 's) can be obtained as described in Griffiths (1972). Drawing on Kalirajan and Obwona (1994), the assumptions underlying model (2) are as follows:

(i) Technical efficiency is achieved by adopting the best practice techniques, which involve the efficient use of inputs. Technical efficiency stems from two sources: (1) the efficient use of each input which contributes individually to technical efficiency and can be measured by the magnitudes of the varying slope coefficients, $\alpha_{k i}$ 's; and (2) any other firm-specific intrinsic characteristics which are not explicitly included may produce a combined contribution over and above the individual contributions. This 'lump sum' contribution, if any, can be measured by the varying intercept term.

(ii) The highest magnitude of each response coefficient and the intercept form the production coefficients of the potential frontier production function. Let $\left(\alpha^{*}\right.$ s) and $\left(\gamma^{*}\right.$ s) be the estimates of the coefficients of the frontier production function, that is,

$$
\alpha_{k}^{*}=\max _{i}\left\{\alpha_{k i}\right\}, \gamma_{j}^{*}=\max _{i}\left\{\gamma_{j i}\right\}, \mathrm{k}=1, \ldots \mathrm{K} ; \mathrm{i}=1, \ldots, \mathrm{N} \text { and } j=2, \ldots, \mathrm{T} \text {. }
$$

Now the potential frontier output for individual observations can be calculated as

$$
\ln Y_{i t}^{*}=\alpha_{1}^{*}+\sum_{j=2}^{T} \gamma_{j}^{*} D_{j i t}+\sum_{k=2}^{K} \alpha_{k}^{*} \ln X_{k i t} ; \mathrm{i}=1, \ldots \mathrm{N}
$$

where $X_{k i t}$ is the actual level of the $k^{\text {th }}$ input used by the $i^{\text {th }}$ firm in period t. A measure of technical efficiency denoted by, say, $E$, can be defined as

$$
E_{i t}=\frac{Y_{i t}}{\exp \left(\ln Y_{t}^{*}\right)}
$$

where the numerator refers to the realized output and the denominator shows the potential frontier output calculated from (3). 


\subsection{Decomposition of TFP growth}

Figure 1, which is in logarithms, illustrates the decomposition of total output growth into input growth, technical progress and technical efficiency improvement (Kalirajan, Obwona and Zhao, 1996). In periods 1 and 2 , the firm faces production frontiers $F_{1}$ and $F_{2}$ respectively. If a given firm has been technically efficient, output would be $\mathrm{y}_{1} *$ in period 1 and $\mathrm{y}_{2} *$ in period 2 . On the other hand, if the firm is technically inefficient and does not operate on its frontier, then the firm's realized output is $\mathrm{y}_{1}$ in period 1 and $\mathrm{y}_{2}$ in period 2 .

Figure 1: Decomposition of Output Growth

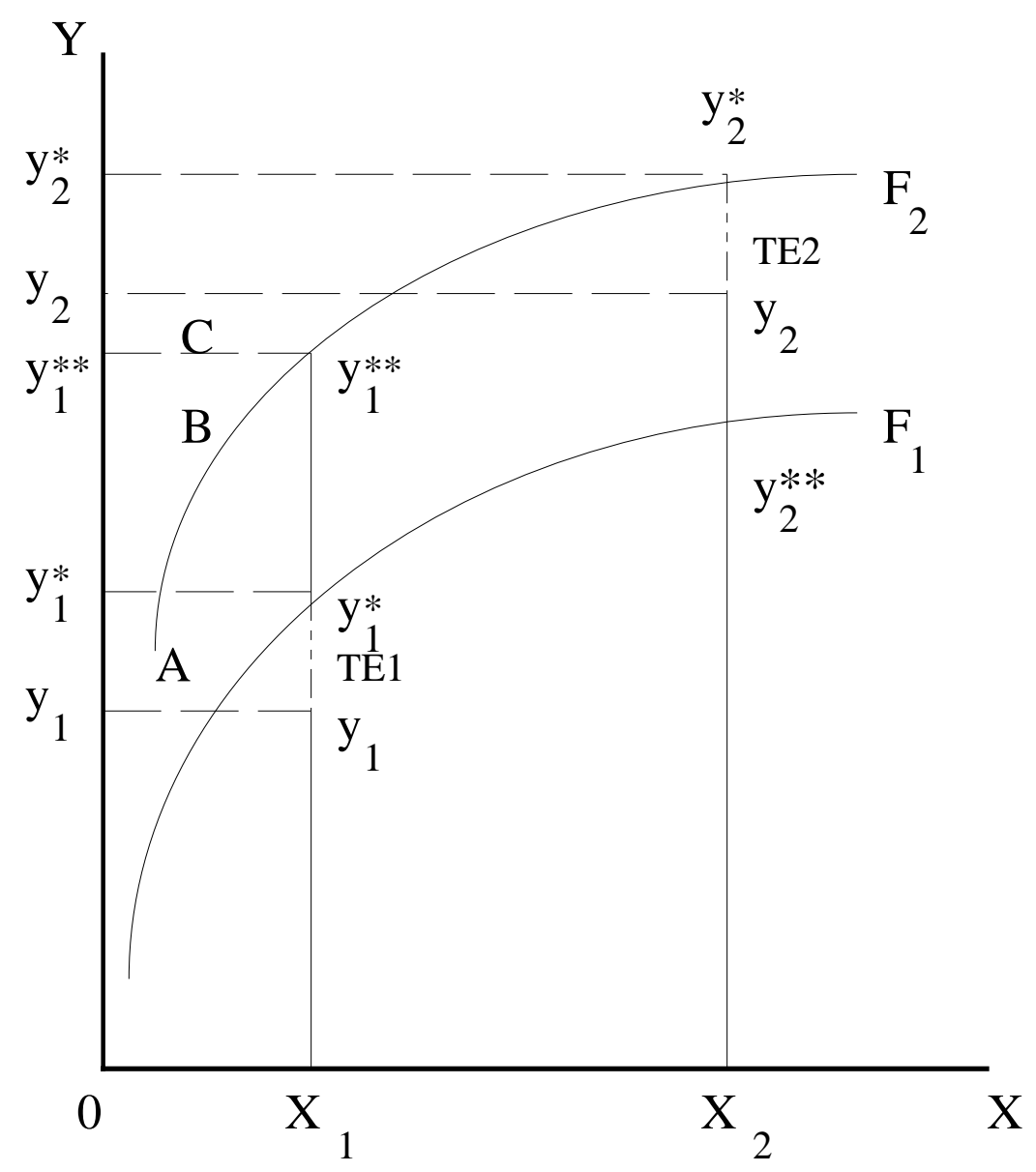

Technical inefficiency is measured by the vertical distance between the frontier output and the realized output of a given firm, that is, TE1 in period 1 and TE2 in period 2, respectively. 
Hence, the change in technical efficiency over time is the difference between TE1 and TE2. Technological improvement is measured by the distance between frontier $F_{2}$ and frontier $F_{1}$, that is, $\left(\mathrm{y}_{2} *-\mathrm{y}_{2} * *\right)$ using $\mathrm{x}_{2}$ input levels or $\left(\mathrm{y}_{1}^{* *}-\mathrm{y}_{1} *\right)$ using $\mathrm{x}_{1}$ input levels. Denoting the contribution of input growth to output growth (between periods 1 and 2) as $\Delta y_{x}$, the total output growth, $\left(\mathrm{y}_{2}\right.$ $\mathrm{y}_{1}$ ), can be decomposed into three components: input growth, technological progress and technical efficiency change.

Referring to Figure 1, the decomposition can be shown as follows:

$$
\begin{aligned}
& \mathrm{D}=\mathrm{y}_{2}-\mathrm{y}_{1} \\
& =\mathrm{A}+\mathrm{B}+\mathrm{C} \\
& =\left[\mathrm{y}_{1} *-\mathrm{y}_{1}\right]+\left[\mathrm{y}_{1} * *-\mathrm{y}_{1} *\right]+\left[\mathrm{y}_{2}-\mathrm{y}_{1} * *\right] \\
& =\left[\mathrm{y}_{1}^{*}-\mathrm{y}_{1}\right]+\left[\mathrm{y}_{1} * *-\mathrm{y}_{1} *\right]+\left[\mathrm{y}_{2}-\mathrm{y}_{1} * *\right]+\left[\mathrm{y}_{2} *-\mathrm{y}_{2} *\right] \\
& =\left[\mathrm{y}_{1}^{*}-\mathrm{y}_{1}\right]+\left[\mathrm{y}_{1} * *-\mathrm{y}_{1} *\right]-\left[\mathrm{y}_{2} *-\mathrm{y}_{2}\right]+\left[\mathrm{y}_{2} * \mathrm{y}_{1} * *\right] \\
& =\left\{\left[\mathrm{y}_{1} *-\mathrm{y}_{1}\right]-\left[\mathrm{y}_{2} *-\mathrm{y}_{2}\right]\right\}+\left[\mathrm{y}_{1} * *-\mathrm{y}_{1} *\right]+\left[\mathrm{y}_{2} * \mathrm{y}_{1} * *\right] \\
& =\{\mathrm{TE} 1-\mathrm{TE} 2\}+\mathrm{TC}+\Delta y_{x}
\end{aligned}
$$

where

$$
\begin{aligned}
& \mathrm{y}_{2}-\mathrm{y}_{1}=\text { Output growth } \\
& \text { TE1 }- \text { TE2 }=\text { Technical efficiency change } \\
& \text { TC }=\text { Technical change and } \\
& \Delta y_{x}=\text { Output growth due to input growth. }
\end{aligned}
$$

Solow (1957) attributed output growth to input growth and technical change. The decomposition in (5) enriches Solow's dichotomy by attributing observed output growth to movements along a path on or beneath the production frontier (input growth), movement toward or away from the production frontier (technical efficiency change), and shifts in the production frontier (technological progress).

\section{Data}

The economies examined are Japan, Hong Kong, Singapore, and Korea. The data are mainly from various years of the United Nations publication, Industrial Statistics Yearbook. For each economy, twenty manufacturing sectors (which have no missing data for all the four 
economies) are used. The sectors and there SIC classification numbers are listed in Table 1. The data series are value added and fixed capital formation, measured in local currency units, and employment, measured in numbers. The series of value added and fixed capital formation are at current prices, so we apply GDP deflators to convert these series into constant price based on year 1985. GDP deflators for Hong Kong, Singapore, Korea, and Japan are from the IFS database. For cross-country estimates, we convert the local currency measures to a common unit, US dollars, using exchange rates from the IFS database.

\section{Table 1: Manufacturing Sectors}

\begin{tabular}{ll}
\hline 311-Food Products & 342-Printing, Publishing \\
313-Beverages & 351-Industrial Chemicals \\
314-Tobacco & 355-Rubber Products \\
321-Textiles & 356-Plastic Products \\
322-Wearing Apparel & 381-Metal Products \\
323-Leather Products & 382-Machinery n.e.c. \\
324-Footwear & 383-Electrical Machinery \\
331-Wood Products & 384-Transport Equipment \\
332-Furniture, Fixtures & 385-Professional goods \\
341-Paper and Products & 390-Other industries \\
\hline
\end{tabular}

Source: Industrial Statistics Yearbooks, United Nations

Following Jorgenson, Gollop and Fraumeni (1987), the existence of a value added function in the production process described by the production function could be tested employing linear and non-linear separability conditions. The present study confines itself to the linear separability case only. Consequently, the value added function has been selected for further analysis. We use value added in producer prices for Hong Kong, Japan and Korea, and value added in factor prices for Singapore. 
For the regression of the varying coefficient model, the net value added is the dependent variable for each sector, and capital stock and employment are the independent variables. Our sample covers the period from 1987 to 1993. We have used the perpetual inventory method to construct the capital stock, with 1978 as the benchmark, under 0\% depreciation and $5 \%$ depreciation, i.e.,

$$
\mathrm{K}_{\mathrm{it}}=\left(1-\mathrm{d}_{\mathrm{i}}\right) \mathrm{K}_{\mathrm{it}-1}+\mathrm{I}_{\mathrm{it}}
$$

where

$$
\begin{aligned}
& K_{i t} \text { is capital stock of sector } i \text { at period } t \\
& d_{i} \text { is depreciation rate of sector } i \\
& I_{i t} \text { is capital formation in sector } i \text { at period } t .
\end{aligned}
$$

To give an idea of how the four economies were doing during the period analyzed, Table 2 shows the GDP growth rates during 1987 to 1993. Note that Japan's growth rate has been decreasing significantly after 1990. Hong Kong's growth rate has been relatively stable after 1987, though there was a dip in 1989-90. Singapore's growth rate has been quite strong during the period, and Korea's was showing a decreasing trend over this period, though the rate has been still high.

\section{Table 2: GDP Growth Rates}

\begin{tabular}{lrrrrrrr}
\hline GDP\% change & $\mathbf{1 9 8 7}$ & $\mathbf{1 9 8 8}$ & $\mathbf{1 9 8 9}$ & $\mathbf{1 9 9 0}$ & $\mathbf{1 9 9 1}$ & $\mathbf{1 9 9 2}$ & $\mathbf{1 9 9 3}$ \\
\hline Hong Kong & 12.2 & 7.7 & 2.5 & 3.3 & 4.9 & 6.1 & 6.0 \\
Singapore & 9.3 & 11.0 & 9.2 & 8.6 & 6.9 & 6.3 & 11.9 \\
Korea & 10.4 & 9.9 & 5.9 & 8.6 & 8.8 & 5.3 & 5.3 \\
Japan & 4.2 & 6.2 & 4.8 & 5.1 & 3.8 & 1.0 & 0.3 \\
\hline
\end{tabular}

Source: Key Indicators of Developing Asian and Pacific Countries, International Department, Bank of Japan

To see how closely the manufacturing sectors of the four economies were integrated with each other during the period, we calculated pairwise simple correlations of the sectoral growth rates, as reported in Table 3. A positive correlation coefficient indicates that the manufacturing 
sectors of the two economies were, on balance, moving in step during in that year. The 22 of the 36 positive correlation coefficients may not provide any overwhelming evidence that these four economies moved together. In particular, short run changes in manufacturing in the three smaller economies do not seem to be influenced heavily by changes in Japan.

Table 3: Correlation of Growth Rates in Manufacturing

\begin{tabular}{|c|c|c|c|c|c|c|}
\hline Period & HK-Japan & HK-Korea & HK-Sing & Japan-Korea & Japan-Sing & Korea-Sing \\
\hline $1987-88$ & 0.334 & 0.071 & -0.158 & 0.638 & 0.477 & 0.226 \\
\hline $1988-89$ & 0.034 & 0.026 & -0.293 & 0.321 & -0.025 & 0.366 \\
\hline $1989-90$ & -0.234 & -0.037 & 0.130 & 0.310 & -0.016 & -0.195 \\
\hline 1990-91 & 0.465 & -0.257 & 0.277 & -0.054 & 0.288 & -0.032 \\
\hline 1991-92 & 0.004 & -0.371 & 0.005 & -0.015 & -0.135 & 0.011 \\
\hline $1992-93$ & 0.193 & 0.526 & 0.193 & 0.073 & 0.242 & -0.079 \\
\hline
\end{tabular}

Source: Calculated from Industrial Statistics Yearbooks, United Nations

While the four economies all had positive growth during the years that we analyze, some of their manufacturing sectors were shrinking during this time. Negative growth rates will require that our results be interpreted with some care. We will return to this issue in Sections 5 and 6, when we present our results. Here we note that the issue is particularly relevant for Hong Kong after 1989, with at least half of the sectors having negative growth rates of value added during 1989-90, 1990-91 and 1992-93. The negative growth rates make the decomposition meaningless. A similar problem occurs for Japan during 1991-92 and 1992-93, with negative growth rates in at least half the sectors. Korea and Singapore's output growth rates are in large part positive for the entire sample periods. In the case of inputs, both employment and the constructed capital stock measure showed increases in the vast majority of sectors and years in each country. 


\section{Results: Single Country Regressions}

Before presenting the results of this section, we offer some clarification on possible interpretation of the varying coefficients frontier production function estimates. It is worth noting that the frontier production function is similar to the Meta production function. In both cases, a micro concept has been used to a macroeconomic analysis. In the varying coefficients frontier production function approach, sector specific production characteristics are modeled by allowing variations in the production coefficients across manufacturing sectors within a country. However, a Cobb Douglas framework models the production technology. If one sector is on the frontier and another is below it, this obviously is not the result of differences in efficiency at the sectoral engineering level. Nevertheless, we can interpret the sector that is below the frontier as being less efficient in the sense that its ability to create value added from its given inputs of capital and labor is lower than another sector.

We estimated frontier production functions for each economy for each of the seven years, 1987-93 inclusive. Using these estimated frontiers, we carried out productivity decompositions, as illustrated in Figure 1, using all possible pairs of years. Hence, the decompositions were performed for time spans of one, two, three, four, five and six years. The results were not significantly affected by assuming either a $5 \%$ depreciation rate or $0 \%$ depreciation rate. Here we report only the results for a $0 \%$ depreciation rate. Since results for shorter periods are less likely to reflect factors that determine long run growth patterns, we report results only for four, five and six year spans. For four-year and five-year spans, we report only the number of positive signs out of twenty sectors. For the full six-year span, we report the detailed results.

Before we look at the results by economy, we note that in many cases measured contributions are negative. The possible interpretations of negative changes need some elaboration. High technological progress can plausibly coexist with deteriorating technical efficiency, due to failures in achieving technological mastery or due to adjustment costs in the face of quasi-fixed vintages of capital. On the other hand, negative estimated technological change is harder to interpret. The explanation we offer is that shifts in industrial policy or market conditions may be what are reflected in inward shifts of the estimated frontier, rather than technological regress in a pure engineering sense. 
We next present the results for the four economies, in alphabetical order: Hong Kong, Japan, Singapore and South Korea.

\section{(1) Decomposition results for Hong Kong}

Over the period of analysis, several components of Hong Kong's manufacturing sector were shrinking, complicating the interpretation of our estimates. Looking at four and five year spans in Table 4, we can see that the majority of sectors had negative growth rates. In most cases, with the exception of 1989-93, estimated contributions of technical efficiency change (TEC) were almost always negative, and outweighed the positive contributions of technological progress (TP), leading to negative TFP growth. These results are somewhat surprising, since they would be consistent with the kind of story that Young has sought to tell for Singapore, as an economy trying to push out its frontier too quickly to allow efficiency to keep up. The decomposition results for 1987-93 are presented in detail in Table 5.

\section{Table 4: Number of Positive Signs, Hong Kong}

\begin{tabular}{lccccc}
\hline Period & Growth Rate & TEC & TP & TFPG & Inputs \\
\hline $1987-91$ & 8 & 0 & 20 & 2 & 20 \\
$1988-92$ & 6 & 0 & 20 & 1 & 20 \\
$1989-93$ & 6 & 7 & 4 & 0 & 16 \\
$1987-92$ & 8 & 0 & 20 & 0 & 20 \\
$1988-93$ & 5 & 1 & 16 & 0 & 16 \\
\hline
\end{tabular}

The results in Table 5 are quite consistent with the story we have just outlined above. Technological progress has a positive contribution in 14 of 20 sectors, while technical efficiency change is negative in every single sector. The sum of these, or what is usually termed TFPG, is negative in every case. Again, it must be noted that 12 of the 20 sectors recorded negative changes in value added over the period, and this means that the results for Hong Kong must be viewed with great caution. 
Table 5: Sources of Growth Decomposition for Hong Kong, 1987-93

\begin{tabular}{lcccc}
\hline Sector & Growth & TEC & TP & Inputs \\
\hline Food Products & 0.26 & -0.87 & 0.33 & 0.80 \\
Beverages & 0.05 & -0.42 & 0.09 & 0.37 \\
Tobacco & 0.62 & -0.01 & -0.20 & 0.84 \\
Textiles & -0.50 & -1.93 & 1.04 & 0.39 \\
Wearing Apparel & -0.65 & -1.99 & 1.11 & 0.23 \\
Leather Products & -0.84 & -0.64 & -0.28 & 0.08 \\
Footwear & -2.82 & -2.43 & -0.18 & -0.20 \\
Wood Products & -0.86 & -0.79 & -0.38 & 0.30 \\
Furniture, Fixtures & -1.53 & -1.28 & -0.15 & -0.11 \\
Paper and Products & 0.10 & -1.01 & 0.35 & 0.76 \\
Printing, Publishing & 0.39 & -1.13 & 0.66 & 0.86 \\
Industrial Chemicals & 0.09 & -0.30 & 0.19 & 0.20 \\
Rubber Products & -1.05 & -0.49 & -0.47 & -0.08 \\
Plastic Products & -1.01 & -1.97 & 0.90 & 0.06 \\
Metal Products & -0.48 & -1.50 & 0.80 & 0.22 \\
Machinery n.e.c. & 0.35 & -1.22 & 0.56 & 1.01 \\
Electrical Machinery & -0.60 & -1.96 & 1.08 & 0.27 \\
Transport Equipment & 0.27 & -0.50 & 0.34 & 0.43 \\
Professional goods & -0.35 & -1.27 & 0.58 & 0.35 \\
Other industries & -0.45 & -1.36 & 0.46 & 0.46 \\
\hline
\end{tabular}

\section{(2) Decomposition results for Japan}

Results for Japan are presented the same format as those for Hong Kong, in Tables 6 and 7. Table 6 reports signs of the components of the decomposition, for four and five year spans, while Table 7 gives detailed results for the six-year period, 1987-93. The estimated production frontier coefficients for Japan were quite plausible and stable, and suggest close to constant returns to scale. In Table 6, almost all the input contributions to growth are positive for the different time spans. Technical efficiency changes are almost all positive as well. However, technological progress estimates are mostly negative. Furthermore, the magnitudes of the technical efficiency changes are small in general compared to those of technological progress, and therefore TFP growth rates are almost all negative. Table 7 shows similar results for the full six-year time span. Thus, this estimation technique suggests that Japan's economic growth in these sectors for the 
period of analysis was mainly attributable to inputs growth. Drawing on Abramovitz (1993) and Hayami and Ogasawara (1999), it may be argued that the accumulation of human-capitalaugmented labour, which can be gauged by the technical efficiency improvements, was not faster than that of physical capital during the period of analysis in Japan.

Table 6: Number of Positive Signs, Japan

\begin{tabular}{lccccc}
\hline Period & Growth Rate & TEC & TP & TFPG & Inputs \\
\hline $1987-91$ & 20 & 18 & 1 & 4 & 19 \\
$1988-92$ & 16 & 18 & 0 & 1 & 19 \\
$1989-93$ & 8 & 19 & 0 & 1 & 19 \\
$1987-92$ & 19 & 18 & 1 & 1 & 19 \\
$1988-93$ & 10 & 18 & 0 & 1 & 19 \\
\hline
\end{tabular}

\section{(3) Decomposition results for Singapore}

Results for Singapore are presented in Tables 8 and 9. The estimated production frontier coefficients for Singapore were again quite plausible and stable, and suggest close to constant returns to scale. In general, the pattern of results is closer to that of Japan than to Hong Kong, although there are some differences. In particular, the output growth rates and estimated input contributions are much greater for Singapore than for Japan. Another difference is that 14 of the TEC signs are negative for 1987-93 (Table 9), unlike Japan where they were positive in general. Again, the main conclusion is that input growth has been the major factor in output growth in Singapore's manufacturing sectors.

There is an additional pattern that shows up when one considers shorter time spans of 1-3 years. During the first half of the sample period, technical efficiency changes are largely positive while technological progress estimates are largely negative. This indicates that Singapore has been employing a human-capital-using bias in technological progress in that period, which is plausible because Singapore had negative growth rates for 1985 and 1986. During the next half of the period, technical efficiency changes become negative and technological improvements are positive. It is possible to relate this shift to changes in 
Singapore's economy to its economic policy over this period, which emphasized the importance of new manufacturing investments and upgrading the operations of the existing manufacturing plants (Ministry of Trade and Industry, 1986).

Table 7: Sources of Growth Decomposition for Japan, 1987-93

\begin{tabular}{lrrrr}
\hline Sector & Growth & TEC & TP & Inputs \\
\hline Food Products & 0.16 & 0.24 & -0.42 & 0.34 \\
Beverages & 0.04 & -0.05 & -0.25 & 0.34 \\
Tobacco & 0.27 & 0.51 & -0.01 & -0.24 \\
Textiles & -0.14 & 0.10 & -0.44 & 0.20 \\
Wearing Apparel & 0.03 & 0.27 & -0.52 & 0.29 \\
Leather Products & -0.07 & 0.07 & -0.43 & 0.29 \\
Footwear & 0.01 & 0.11 & -0.38 & 0.28 \\
Wood Products & 0.00 & 0.23 & -0.44 & 0.21 \\
Furniture, Fixtures & 0.04 & 0.17 & -0.41 & 0.28 \\
Paper and Products & 0.08 & 0.06 & -0.30 & 0.32 \\
Printing, Publishing & 0.19 & 0.16 & -0.40 & 0.42 \\
Industrial Chemicals & 0.07 & 0.01 & -0.22 & 0.28 \\
Rubber Products & 0.10 & 0.09 & -0.31 & 0.31 \\
Plastic Products & 0.19 & 0.16 & -0.36 & 0.39 \\
Metal Products & 0.25 & 0.25 & -0.42 & 0.42 \\
Machinery n.e.c. & 0.16 & 0.19 & -0.39 & 0.36 \\
Electrical Machinery & 0.08 & 0.17 & -0.39 & 0.30 \\
Transport Equipment & 0.18 & 0.17 & -0.33 & 0.33 \\
Professional goods & -0.04 & 0.14 & -0.33 & 0.15 \\
Other industries & 0.16 & 0.25 & -0.39 & 0.29 \\
\hline
\end{tabular}


Table 8: Number of Positive Signs, Singapore

\begin{tabular}{lccccc}
\hline Period & Growth Rate & TEC & TP & TFPG & Inputs \\
\hline $1987-91$ & 15 & 15 & 0 & 1 & 20 \\
$1988-92$ & 13 & 15 & 0 & 1 & 19 \\
$1989-93$ & 7 & 4 & 3 & 0 & 19 \\
$1987-92$ & 14 & 7 & 0 & 0 & 20 \\
$1988-93$ & 14 & 15 & 0 & 1 & 19 \\
\hline
\end{tabular}

Table 9: Sources of Growth Decomposition for Singapore, 1987-93

\begin{tabular}{lcccc}
\hline Sector & Growth & TEC & TP & Inputs \\
\hline Food Products & 0.23 & -0.04 & -0.27 & 0.55 \\
Beverages & 0.11 & -0.48 & -0.25 & 0.84 \\
Tobacco & 0.50 & 0.26 & -0.28 & 0.52 \\
Textiles & -0.09 & -0.23 & -0.20 & 0.35 \\
Wearing Apparel & -0.31 & -0.65 & 0.00 & 0.34 \\
Leather Products & 0.78 & -0.12 & 0.08 & 0.82 \\
Footwear & -0.04 & -0.02 & -0.03 & 0.00 \\
Wood Products & -0.28 & -0.05 & -0.23 & 0.01 \\
Furniture, Fixtures & 0.18 & -0.07 & -0.07 & 0.33 \\
Paper and Products & 0.28 & -0.07 & -0.30 & 0.65 \\
Printing, Publishing & 0.57 & 0.15 & -0.26 & 0.68 \\
Industrial Chemicals & -0.28 & -0.74 & -0.42 & 0.88 \\
Rubber Products & 0.15 & -0.06 & -0.21 & 0.42 \\
Plastic Products & 0.75 & 0.20 & -0.23 & 0.78 \\
Metal Products & 0.53 & 0.14 & -0.30 & 0.68 \\
Machinery n.e.c. & 0.50 & 0.20 & -0.33 & 0.63 \\
Electrical Machinery & 0.53 & 0.09 & -0.33 & 0.77 \\
Transport Equipment & 0.43 & -0.03 & -0.29 & 0.75 \\
Professional goods & 0.52 & 0.09 & -0.21 & 0.64 \\
Other industries & -0.56 & -0.88 & -0.13 & 0.45 \\
\hline
\end{tabular}




\section{(4) Decomposition results for South Korea}

Results for South Korea are presented in Tables 10 and 11. They are quite different from the other three countries analyzed, particularly because TFP growth contributions were positive in over half of the sectors for almost all the time spans analyzed. On average, about half of the sectors have positive technical efficiency changes, while estimated technological progress has also been positive in the majority of the sectors (Table 10). However, it should be noted that the estimated input contributions to growth are positive and large, and in this respect the evidence for South Korea is similar to that for the other three countries. The estimated production frontier coefficients for South Korea were quite plausible and stable, but suggest decreasing returns to scale.

\section{Table 10: Number of Positive Signs, South Korea}

\begin{tabular}{lccccc}
\hline Period & Growth Rate & TEC & TP & TFPG & Inputs \\
\hline $1987-91$ & 18 & 10 & 18 & 16 & 18 \\
$1988-92$ & 16 & 11 & 15 & 11 & 18 \\
$1989-93$ & 16 & 12 & 12 & 13 & 19 \\
$1987-92$ & 17 & 13 & 11 & 13 & 18 \\
$1988-93$ & 16 & 12 & 13 & 11 & 18 \\
\hline
\end{tabular}

\section{Discussion}

One possible explanation for the different results for Hong Kong, as compared to previous work, is that we have restricted attention to manufacturing. Hong Kong's growth may come not from manufacturing, but from services, particularly finance and international trade. For Singapore, our results are not inconsistent with those of Young (1994), though we use a very different method. Our results in general are consistent with those of Kim and Lau (1994), in emphasizing the role of input growth. In our case, we have focused on manufacturing, and we have not pooled different economies. We do so in the next section, which is more similar in this respect to Kim and Lau's analysis, though they do not allow for observations to be inside the frontier. However, our results do suggest that pooling economies can be problematic, since the results for South 
Korea stand out as somewhat different from the other economies in this period, and indicate more robust, technology driven manufacturing growth.

Table 11: Sources of Growth Decomposition for South Korea, 1987-93

\begin{tabular}{lcrrr}
\hline Sector & Growth & TEC & \multicolumn{1}{c}{ TP } & Inputs \\
\hline Food Products & 0.61 & 0.32 & -0.08 & 0.37 \\
Beverages & 0.18 & 0.13 & -0.11 & 0.16 \\
Tobacco & -0.09 & -0.01 & -0.05 & -0.03 \\
Textiles & 0.13 & -0.07 & -0.07 & 0.27 \\
Wearing Apparel & 0.33 & -0.06 & 0.15 & 0.24 \\
Leather Products & 0.21 & -0.20 & 0.11 & 0.30 \\
Footwear & 1.16 & 0.26 & 0.14 & 0.76 \\
Wood Products & 0.81 & 0.47 & 0.02 & 0.32 \\
Furniture, Fixtures & 1.16 & -0.17 & 0.11 & 1.22 \\
Paper and Products & 0.46 & 0.05 & -0.06 & 0.47 \\
Printing, Publishing & 0.76 & 0.22 & 0.03 & 0.51 \\
Industrial Chemicals & 0.54 & 0.22 & -0.23 & 0.55 \\
Rubber Products & -0.51 & -0.49 & 0.06 & -0.08 \\
Plastic Products & 1.05 & 0.30 & -0.01 & 0.75 \\
Metal Products & 0.67 & 0.21 & -0.02 & 0.48 \\
Machinery n.e.c. & 0.87 & 0.34 & -0.07 & 0.60 \\
Electrical Machinery & 0.48 & 0.12 & -0.08 & 0.44 \\
Transport Equipment & 0.72 & 0.30 & -0.14 & 0.56 \\
Professional goods & 0.16 & -0.22 & 0.08 & 0.30 \\
Other industries & -0.16 & -0.41 & 0.12 & 0.14 \\
\hline
\end{tabular}




\section{Results: Cross-Country Regressions}

One possible criticism of the approach behind the results presented above is that sectors that are too dissimilar are pooled together in estimating the production frontier. To some extent, this criticism can be leveled against any of the dozens of aggregate studies using production functions, as well as those using growth accounting. We offered an interpretation of our manufacturing frontiers in terms of capturing the manner and efficiency of allocation of labor and capital, but it is worth checking an alternative approach to the data. In this section, we group sectors by their nearness in terms of their SIC classifications, with the goal of capturing sectors that are likely to have more similar technologies. In order to have enough degrees of freedom, we have to pool across the four economies (as Kim and Lau did). The frontier approach is perhaps more natural in this case, since it allows for the possibility of varying efficiencies across industries and across the countries.

\section{1) Traditional Sectors}

One typically thinks of sectors such as food products and textiles as being traditional sectors that will be emphasized in early stages of development. In the case of industrialized countries, these sectors may actually be protected, and less efficient. One might also expect that the possibilities for technological progress in these sectors would be limited. We grouped together 7 sectors, namely, 311, 313-4 and 312-4 (see Table 1) to capture such ideas. Therefore there were 28 observations in this frontier estimation. Results for the time span 1987-93 are presented in Table 12.

The results again support the role of input growth as the major component of value added growth. While TEC is positive in seven cases, and TP in nine, their sum, or TFPG, is positive in only one case. This indicates slightly fewer positive cases than the results for these sectors in the single country regressions (Tables 5, 7, 9 and 11); but the results are, on the whole, not inconsistent with the earlier estimates. The estimated frontier has reasonable coefficients, with slightly increasing returns to scale being suggested. 
Table 12: Sources of Growth Decomposition for Traditional Sectors, 1987-93

\begin{tabular}{llrrrrr}
\hline Economy & Sector & Growth & \multicolumn{1}{c}{ TEC } & \multicolumn{1}{c}{ TP } & \multicolumn{1}{c}{ TFPG } & Inputs \\
\hline Hong Kong & Food Products & 0.26 & -0.16 & -0.19 & -0.36 & 0.62 \\
& Beverages & 0.05 & -0.10 & -0.12 & -0.22 & 0.27 \\
& Tobacco & 0.62 & 0.00 & -0.03 & -0.02 & 0.65 \\
& Textiles & -0.50 & -0.29 & -0.46 & -0.75 & 0.25 \\
& Wearing Apparel & -0.65 & -0.28 & -0.47 & -0.75 & 0.10 \\
& Leather Products & -0.84 & -0.82 & 0.03 & -0.79 & -0.05 \\
& Footwear & -2.82 & -2.41 & 0.00 & -2.41 & -0.41 \\
& Food Products & 0.23 & -0.21 & -0.12 & -0.33 & 0.56 \\
& Beverages & 0.11 & -0.79 & 0.06 & -0.74 & 0.85 \\
& Tobacco & 0.50 & -0.18 & 0.16 & -0.02 & 0.52 \\
& Textiles & -0.09 & -0.49 & 0.06 & -0.44 & 0.35 \\
& Wearing Apparel & -0.31 & -0.58 & -0.06 & -0.64 & 0.33 \\
& Leather Products & 0.78 & -0.45 & 0.39 & -0.06 & 0.84 \\
& Footwear & -0.04 & -0.30 & 0.27 & -0.03 & -0.02 \\
& Food Products & 0.61 & 0.32 & -0.36 & -0.03 & 0.64 \\
& Beverages & 0.18 & 0.03 & -0.20 & -0.16 & 0.34 \\
& Tobacco & -0.09 & -0.07 & -0.04 & -0.11 & 0.03 \\
& Textiles & 0.13 & 0.06 & -0.44 & -0.38 & 0.51 \\
& Wearing Apparel & 0.33 & 0.09 & -0.22 & -0.12 & 0.46 \\
& Leather Products & 0.21 & -0.30 & -0.07 & -0.36 & 0.57 \\
& Footwear & 1.16 & -0.03 & -0.02 & -0.04 & 1.21 \\
& Food Products & 0.16 & 0.05 & -0.45 & -0.40 & 0.56 \\
& Beverages & 0.04 & -0.37 & -0.21 & -0.57 & 0.61 \\
& Tobacco & 0.27 & 0.64 & -0.27 & 0.37 & -0.10 \\
& Textiles & -0.14 & -0.28 & -0.33 & -0.60 & 0.47 \\
& Wearing Apparel & 0.03 & -0.37 & -0.14 & -0.51 & 0.54 \\
& Leather Products & -0.07 & -0.80 & 0.15 & -0.65 & 0.59 \\
& Footwear & 0.01 & -0.62 & 0.14 & -0.48 & 0.49 \\
\hline & & & & & &
\end{tabular}


Table 13: Sources of Growth Decomposition for Intermediate Sectors, 1987-93

\begin{tabular}{llccccr}
\hline Economy & Sector & Growth & TEC & TP & TFPG & Inputs \\
\hline Hong Kong & Wood Products & -0.86 & -0.01 & -0.91 & -0.91 & 0.05 \\
& Furniture, Fixtures & -1.53 & -0.29 & -0.89 & -1.18 & -0.35 \\
& Paper and Products & 0.10 & 0.50 & -0.87 & -0.37 & 0.47 \\
Singapore & Printing, Publishing & 0.39 & 0.64 & -0.85 & -0.21 & 0.61 \\
& Wood Products & -0.28 & 0.68 & -0.91 & -0.23 & -0.05 \\
& Furniture, Fixtures & 0.18 & 0.80 & -0.89 & -0.09 & 0.27 \\
& Paper and Products & 0.28 & 0.58 & -0.91 & -0.33 & 0.61 \\
South Korea & Printing, Publishing & 0.57 & 0.81 & -0.87 & -0.06 & 0.63 \\
& Wood Products & 0.81 & 1.17 & -0.85 & 0.32 & 0.49 \\
& Furniture, Fixtures & 1.16 & 0.17 & -0.85 & -0.68 & 1.84 \\
& Paper and Products & 0.46 & 0.57 & -0.83 & -0.27 & 0.72 \\
& Printing, Publishing & 0.76 & 0.83 & -0.83 & -0.01 & 0.77 \\
& Wood Products & 0.00 & 0.42 & -0.79 & -0.38 & 0.38 \\
& Furniture, Fixtures & 0.04 & 0.38 & -0.81 & -0.43 & 0.48 \\
& Paper and Products & 0.08 & 0.38 & -0.79 & -0.42 & 0.50 \\
& Printing, Publishing & 0.19 & 0.34 & -0.77 & -0.44 & 0.62 \\
\hline
\end{tabular}

\section{2) Intermediate Sectors}

We use the term "intermediate" to reflect these sectors' place in the SIC categories. In this group, we include wood products (331), furniture (332), paper (341) and printing (342). This group is somewhat heterogeneous in terms of how "traditional" the sectors may be, with printing and publishing, in particular, being somewhat different in nature. However, with this caveat, we present the results in Table 13 for the time span 1987-93.

In the case of this group of sectors, TEC is positive in 14 of 16 cases, but TP is negative in every case, and outweighs TEC in general, so that only two cases of TFPG are estimated. This illustrates the potential value of the decomposition of TFPG, since the results for TFPG are very similar to the previous group of sectors, but the decomposition is quite different. Comparing the results to the individual economy decompositions, we see that they are quite similar, with the 
exception of Hong Kong. The results for Hong Kong appear to be slightly improved in terms of plausibility, in the pooled-economy estimations.

\section{3) Modern Sectors}

This group contains 8 sectors, with SIC numbers 351, 355-6 and 381-5, covering various industrial products in metal and chemical industries. One might expect to find evidence for technological progress in this group of sectors. However, the results presented in Table 14 do not support this conjecture in general. While 20 of the 32 TEC estimates have positive signs, the estimates of technological progress are always negative and fairly large, and, as a result, TFPG is positive in only one case.

Compared to the results for the economy-by-economy regressions, the main difference is in the decomposition for Hong Kong, where the signs of TEC and TP are generally reversed from the previous case. In other cases, the results are fairly consistent.

The general conclusion from this alternative analysis, in which we have grouped roughly similar sectors, is that input growth shows up as a major contributor to value added growth in the manufacturing sectors of these economies; technical efficiency change sometimes seems to be important; and technological progress, measured as a shift in the production frontier, does not seem to be significant over this period. Together with the results of the previous section, these results are consistent with earlier studies such as that of Kim and Lau (1994), but they are, in a sense, too strong. Since we find technological progress to be negative, the puzzle is why the frontier should be shifting inward according to our estimates. We turn to this issue in our conclusion. 
Table 14: Sources of Growth Decomposition for Modern Sectors, 1987-93

\begin{tabular}{llrrrrr}
\hline Economy & Sector & Growth & TEC & TP & TFPG & Inputs \\
\hline Hong Kong & Industrial Chemicals & 0.09 & 0.48 & -0.52 & -0.05 & 0.14 \\
& Rubber Products & -1.05 & -0.63 & -0.30 & -0.93 & -0.12 \\
& Plastic Products & -1.01 & -0.35 & -0.65 & -1.00 & -0.01 \\
& Metal Products & -0.48 & 0.00 & -0.62 & -0.62 & 0.14 \\
& Machinery n.e.c. & 0.35 & 0.17 & -0.57 & -0.40 & 0.75 \\
& Electrical Machinery & -0.60 & -0.05 & -0.72 & -0.77 & 0.16 \\
& Transport Equipment & 0.27 & 0.49 & -0.54 & -0.04 & 0.32 \\
& Professional goods & -0.35 & -0.04 & -0.54 & -0.57 & 0.23 \\
Singapore & Industrial Chemicals & -0.28 & -0.58 & -0.55 & -1.12 & 0.84 \\
& Rubber Products & 0.15 & 0.02 & -0.28 & -0.26 & 0.41 \\
& Plastic Products & 0.75 & 0.39 & -0.38 & 0.01 & 0.74 \\
& Metal Products & 0.53 & 0.36 & -0.49 & -0.13 & 0.65 \\
& Machinery n.e.c. & 0.50 & 0.41 & -0.52 & -0.11 & 0.61 \\
& Electrical Machinery & 0.53 & 0.38 & -0.60 & -0.22 & 0.74 \\
& Transport Equipment & 0.43 & 0.19 & -0.47 & -0.28 & 0.71 \\
& Professional goods & 0.52 & 0.24 & -0.33 & -0.10 & 0.62 \\
Japan & Industrial Chemicals & 0.54 & 0.27 & -0.62 & -0.34 & 0.88 \\
& Rubber Products & -0.51 & -0.51 & -0.21 & -0.72 & 0.21 \\
& Plastic Products & 1.05 & 0.15 & -0.29 & -0.14 & 1.19 \\
& Metal Products & 0.67 & 0.24 & -0.34 & -0.10 & 0.77 \\
& Machinery n.e.c. & 0.87 & 0.38 & -0.41 & -0.03 & 0.90 \\
& Electrical Machinery & 0.48 & 0.19 & -0.47 & -0.28 & 0.76 \\
& Transport Equipment & 0.72 & 0.37 & -0.54 & -0.16 & 0.88 \\
& Professional goods & 0.16 & -0.29 & -0.13 & -0.42 & 0.58 \\
& Industrial Chemicals & 0.07 & 0.11 & -0.53 & -0.42 & 0.49 \\
& Rubber Products & 0.10 & -0.19 & -0.23 & -0.42 & 0.52 \\
& Plastic Products & 0.19 & -0.14 & -0.28 & -0.42 & 0.61 \\
& Metal Products & 0.25 & -0.17 & -0.25 & -0.41 & 0.67 \\
& Machinery n.e.c. & 0.16 & -0.01 & -0.40 & -0.41 & 0.57 \\
& Electrical Machinery & 0.08 & 0.04 & -0.47 & -0.43 & 0.52 \\
& Transport Equipment & 0.18 & 0.17 & -0.52 & -0.35 & 0.53 \\
& Professional goods & -0.04 & -0.17 & -0.24 & -0.41 & 0.37 \\
\hline & & & & & & \\
& & &
\end{tabular}




\section{Conclusion}

Unlike earlier studies on TFP growth in East Asian countries, this study has used the varying coefficients frontier framework to measure TFP growth for four Asian economies, Hong Kong, Singapore, South Korea, and Japan. This methodology facilitates decomposing the Solow residual further into two parts: technical efficiency change (output gap or catching up) and technological improvement. This decomposition provides some insight into the analysis of which factor contributed the most to economic growth in these economies.

Our results, while restricted to analysis of 20 manufacturing sectors for the period 198793, certainly are consistent with the view that input growth has been the primary source of East Asian growth. We find some evidence for positive technical efficiency change, but little or no support for the role of pure technological progress. In fact, we typically obtain negative estimates for technological change, measured as a shift in the estimated production frontier. In other words, the production frontier appears to shift inward over the period. Since the sectors we analyze were typically growing in terms of value added during the period (as were the economies overall), what we are finding is that inputs were often growing faster than value added. One possible interpretation of our results is that we are picking up a squeeze of margins in manufacturing sectors in this period. This would be consistent with any evidence of improving efficiency as well. Case study evidence may help to refine and further examine this hypothesis. It is also possible that our frontier estimation technique involves some downward bias against measuring shifts in the frontier, though we do not have a specific reason for this. A third possibility is that capital was being over invested in this period, foreshadowing the financial crisis that occurred later in the 1990s. Finally, some business cycle effects may also be at work in biasing our estimates. This is also a conjecture that we intend to examine in our future research. 


\section{REFERENCES}

Abramovitz, M. (1993), "The search for the sources of growth: Area of ignorance, old and new", Journal of Economic History, 53, 217-243.

Aigner, D. J., C.A.K. Lovell, and P. Schmidt (1977), "Formulation and estimation of stochastic frontier production function models", Journal of Econometrics, 6, 21-37.

Baumol, W. (1986), "Productivity growth, convergence and welfare: what the long-run data show", American Economic Review, 76(5), 1072-85.

Dowrick, S. and Duc-Tho Nguyen (1989), "OECD comparative economic growth 1950-85: catch-up and convergence", American Economic Review, 79(5), 1010-30.

Fare, R., S. Grosskopf, M. Norris and Z. Zhang (1994), "Productivity growth, technical progress and efficiency change in industrialized countries", American Economic Review, 84(1), 66-83.

Felipe, J. (1999), “Total Factor Productivity Growth in East Asia: A Critical Survey,” Journal of Development Studies, v 35 n 4, 1-41.

Fischer, S. (1993), "The Role of Macroeconomic Factors in Growth," Journal of Monetary Economics, 32, 485-512.

Fried, H., C.A. K. Lovell and S. Schmidt (1993), The measurement of productive efficiency, Oxford University Press.

Griffiths, W. E. (1972), "Estimating actual response coefficients in the Hildreth-Houck random coefficient model”, Journal of the American Statistical Association, 67, 633-35.

Hayami, Y. and V.W. Ruttan (1985), Agricultural Development: An International Perspective, Revised Edition, Baltimore: Johns Hopkins University Press.

Hayami, Y. and J. Ogasawara (1999), "Changes in the sources of modern economic growth: Japan compared with the United States", Journal of the Japanese and International Economies, 13, 1-21.

Hildreth, C. and J.P. Houck (1968), "Some estimators for a linear model with random coefficients", Journal of the American Statistical Association, 63, 584-95.

Hughes, H. (1995), "Why have East Asia countries led economic development", Economic Record, 71(212), 88-104.

Jorgenson, D.W., F.M. Gollop and B.M. Fraumeni (1987), Productivity and U.S. Economic Growth, Cambridge, MA: Harvard University Press.

Kalirajan, K.P. and M.B. Obwona (1994), "Frontier Production Function: The Stochastic Coefficients Approach", Oxford Bulletin of Economics and Statistics, 56, 87-96. 
Kalirajan, K.P., M.B. Obwona and S. Zhao (1996), "A Decomposition of Total Factor Productivity Growth: The Case of Chinese Agricultural Growth Before and After Reforms", American Journal of Agricultural Economics 78, 331-38.

Kim, Euysung, "Trade Liberalization and Productivity Growth in Korea Manufacturing Industries Price Production, Market Power, and Scale Efficiency," Seminar paper.

Kim, Jong-Il and L. Lau (1994), "The sources of economic growth in the East Asian newly industrialized countries", Journal of the Japanese and International Economies, 8(3), 235271.

Kim, Jong-Il and L. Lau (1995), "The role of human capital in the economic growth of the East Asian newly industrialized countries", Asia Pacific Economic Review, 1(3), 3-22.

Krugman, Paul (1994), "The myth of Asia's miracle", Foreign Affairs, November/December.

Marti, C., (1996), “Is There an East Asian Miracle?" Union Bank of Switzerland Economic Research Working Paper, October.

Meeusen, W. and J. van den Broeck (1977), "Efficiency estimation from Cobb-Douglas production functions with composed error", International Economic Review, 18, 435-44.

Ministry of Trade and Industry (1986), The Singapore Economy: New Directions, Report of the Economic Committee, Ministry of Trade and Industry, Republic of Singapore.

Nishimizu, M. and J. Page (1982), "Total factor productivity growth, technological progress and technical efficiency change: dimensions of productivity change in Yugoslavia, 19651978", Economic Journal, 92, 920-36.

Oshima, M. (1995), "Trends in productivity growth in the economic transition of Asia and longterm prospects for the 1990s", Asian Economic Journal, 9(21), 89-111.

Singh, N. and H. Trieu (1999), "Accounting for East Asian Growth: Japan, Korea and Taiwan", Indian Economic Review.

Singh, N. and H. Trieu (1997), "The role of R\&D in explaining total factor productivity growth in Japan, Korea and Taiwan", UCSC Dept. of Economics Working Paper.

Solow, R.M. (1957), “Technical change and the aggregate production”, Review of Economics and Statistics, 39(3), 312-20.

Sonobe, T. and K. Otsuka (2001), "A new decomposition approach to growth accounting: Derivation of the formula and its application to prewar Japan", Japan and the World Economy, 13, 1-14.

Summers, R. and A. Heston (1991), "The Penn World Table (Mark 5): an expanded set of international comparisons, 1950-1987", Quarterly Journal of Economics, 106(2), 1-41. 
Young, A. (1992), "A tale of two cities: factor accumulation and technical change in Hong Kong and Singapore", NBER Macroeconomic Annual, NRT Press.

Young, A. (1994), "Lessons from the East Asian NICs: a contrarian view", European Economic Review, 110(3), 641-680.

Young, A. (1995), "The tyranny of numbers: confronting the statistical realities of the East Asian growth experience", Quarterly Journal of Economics, 110(3), 641-680.

World Bank (1993), The East Asian Miracle, a World Bank policy research report, Oxford University Press. 